Lysokon Yulia Yu., Luchynskyi Mykhailo A., Iskiv Mariana O. Morphological features of bone tissue regenerates in experimental animals when using osteotropic drugs for recovery bone defects. Journal of Education, Health and Sport. 2021;11(10):11-17. eISSN 2391-8306. DOI http://dx.doi.org/10.12775/JEHS.2021.11.10.001

https://apcz.umk.pl/JEHS/article/view/JEHS.2021.11.10.001

https://zenodo.org/record/5546462

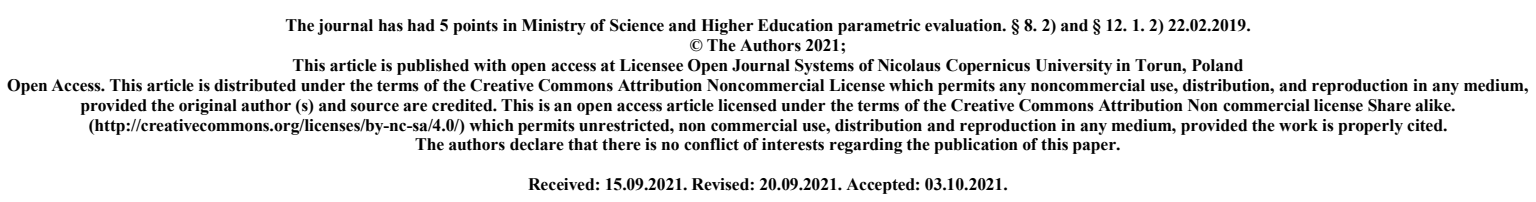

\title{
MORPHOLOGICAL FEATURES OF BONE TISSUE REGENERATES IN EXPERIMENTAL ANIMALS WHEN USING OSTEOTROPIC DRUGS FOR RECOVERY BONE DEFECTS
}

\author{
Yulia Yu. Lysokon ${ }^{1}$, Mykhailo A. Luchynskyi ${ }^{2}$, Mariana O. Iskiv ${ }^{1}$
}

${ }^{1}$ Danylo Halytsky Lviv National Medical University, Department of Therapeutic Dentistry, Lviv, Ukraine

${ }^{2}$ I. Horbachevsky Ternopil State Medical University, Department of Therapeutic Dentistry, Ternopil, Ukraine

Yulia Lysokon orcid.org/ 0000-0002-1722-1825

Mykhailo Luchynskyi orcid.org/0000-0001-7652-0684

Mariana Iskiv orcid.org/0000-0001-5589-1160

\section{Abstract}

The aim of the study was to determine the effectiveness using of osteotropic drugs for the restoration of bone defects.

Materials and methods. The model experiment was performing on male Wistar rats. The animals has been simulated a bone defect into which was implanted:"mp3 Osteobiol" (1st experimental group - 14 animals), PRP coated with fibrin glue (2nd experimental group - 13 animals) and PRP + "mp3 Osteobiol" (3rd experimental group - 15 animals). The histological material were staining with hematoxylin-eosin (according to Van - Gizon). Microscopic studies were performing on a Leica MDE optical microscope at a magnification of $\mathrm{x} 100, \mathrm{x}$ 200.

Results. At the 60th day of observation, after implantation of "mp3 OsteoBiol" + PRP, a pronounced growth of fibrous, loose, not quite mature connective tissue was visualized, with the proliferation of giant multinucleated cells, macrophages, osteoblasts and the formation of osteoids. At the end of the experiment (90th day) in the bone regenerates of animals of group III noted the active formation of the newly formed bone lamellar structure, the formation of osteons, the bone marrow canal was filled with bone marrow.

Conclusion. According to histological studies, it was found that our proposed composition, containing "mp3 OsteoBiol" and PRP, accelerated the process of bone regeneration, compared with the groups where the above agents were used alone, without inflammation, with the formation of bone, which has mature in nature.

Key words: bone tissue, osteotropic drugs, PRP, osteoinduction. 


\section{INTRODUCTION}

The problem of treatment of apical periodontitis is one of the important and not completely solved problems of therapeutic dentistry [1,2]. This is due to the high prevalence of this disease, the complexity of drug manipulations, the high percentage of failures and complications during treatment, as well as usually the lack of stability of the results obtained using known treatments $[3,4,5]$. Traditionally, the success of treatment of destructive forms of chronic periodontitis is associated only with the quality of three main stages: mechanical dilation, antiseptic (drug and physiotherapy) treatments of dental canals and complete obstruction of the root canal system $[6,7,8]$. The choice of drugs for endodontic treatment in most publications is addressed only superficially and is limited to either standard recommendations or the recommended universality of any drug that is not a clinically proven reality [9].

Unfortunately, to date, the management of reparative osteogenesis in the centers of destruction is a very serious difficulty, as existing methods of treatment of destructive forms of apical periodontitis do not involve active exposure to pathological tissues in the center of destruction directly during endodontic treatment $[10,11]$. Therefore, in endodontic practice it is of great interest to study the effectiveness of the use of drugs with pronounced osteoinductive properties, which include, above all, various bone-plastic materials [12, 13].

In our opinion, when carrying out endodontic treatment for destructive forms of chronic apical periodontitis, the combined effect of various therapeutic techniques is important - the use of physiotherapeutic methods of exposure, autologous blood products, the bring out osteotropic drugs behind the apex of the root. This study was conducting as part of the search for optimal osteoplastic material that meets the high requirements that currently exist in modern endodontics

THE AIM

Determine the effectiveness using of osteotropic drugs for the restoration of bone defects.

\section{MATERIALS AND METHODS}

The model experiment was performing on male Wistar rats weighing $200-250$ grams. Under nembutal anesthesia [14], after surgical field was cleaned up to $70 \%$ - with an alcoholic solution of chlorhexidine along the anterior-medial surface of the thigh, was carried out a skin incision length of $5 \mathrm{~cm}$. The muscles were dilated bluntly way and fixed. Using an osteotome on the anterior surface of the rat thigh simulated a bone defect measuring $0.5 \mathrm{~cm}$ [15]. Subsequently, in the bone cavity was implanted "mp3 Osteobiol" (1st experimental group - 14 animals), PRP coated with fibrin glue (2nd experimental group - 13 animals) and PRP + "mp3 Osteobiol" (3rd experimental group - 15 animals) were. The plastic was performing in such a way that the entire cavity of the bone defect was filling. The wound was suturing tightly in layers. An aseptic dressing was applying. Bandaging was performing once a day for 7 days [16].

Collection of material for histological examination was performing by careful separation of muscles from bones, selection of bone segments $1-1.5 \mathrm{~cm}$ long in the area of the bone regenerate. The bone material was fixing in $10 \%$ zinc-formalin buffer for three days. Subsequently, decalcification was performing in a solution of "Trilon B", dehydrated in alcohols with a higher concentration and inpouring into paraffin. Sections $4.0 \mu \mathrm{m}$ thick were staining with hematoxylin-eosin (according to Van - Gizon). Microscopic studies were performing on a Leica MDE optical microscope at a magnification of x 100, x 200 [17].

\section{RESULTS.}

As a result of histological examinations, it was found that on the 30th day of observations during implantation "mp3 OsteoBiol" into a simulated bone defect in 
animals of group I, inflammatory infiltration of the leukocyte shaft type was observed. The surface of the defect was covering with a layer of fibrin, among which polymorphonuclear leukocytes and necrotic masses were visualizing.

At the 60th day of observation, the defect cavity in the bone regenerates of group I animals was filled mainly with connective tissue, with a low content of intercellular substance, with almost complete resorption of the material "mp3 OsteoBiol", the remains of which were surrounded by leukocytes and cell dendrites (Figure 1).
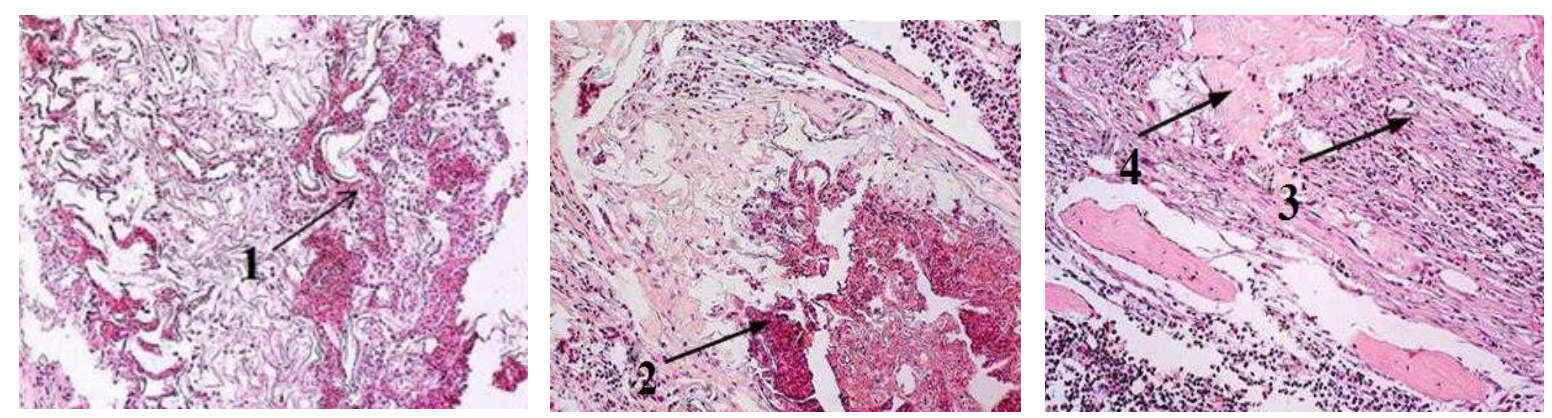

Figure 1. - Histological sections of bone tissue in the area of the simulated defect in the dynamics of the experiment (30th, 60th, 90th day) in group I. The arrows indicate: 1 polymorphonuclear leukocytes; 2 - inflammatory reaction; 3 - coarse fibrous connective tissue; 4 -newly formed bone tissue. Hematoxylin - eosin staining. Magnification x 100.

At the end of the experiment (90th day) in-group I rats, when filling the simulated bone defect with the drug "mp3 OsteoBiol", the formation of newly formed bone was noting, but in the center of the defect were tracing layers of dense unformed connective tissue.

Histological examination of bone regenerates of group II rats, where the simulated bone defect was filling with PRP the 30th day of observation, in the center of bone regeneration was visualized coarse fibrous tissue with perifocal vascular proliferation and vascular proliferation (Figure 2).
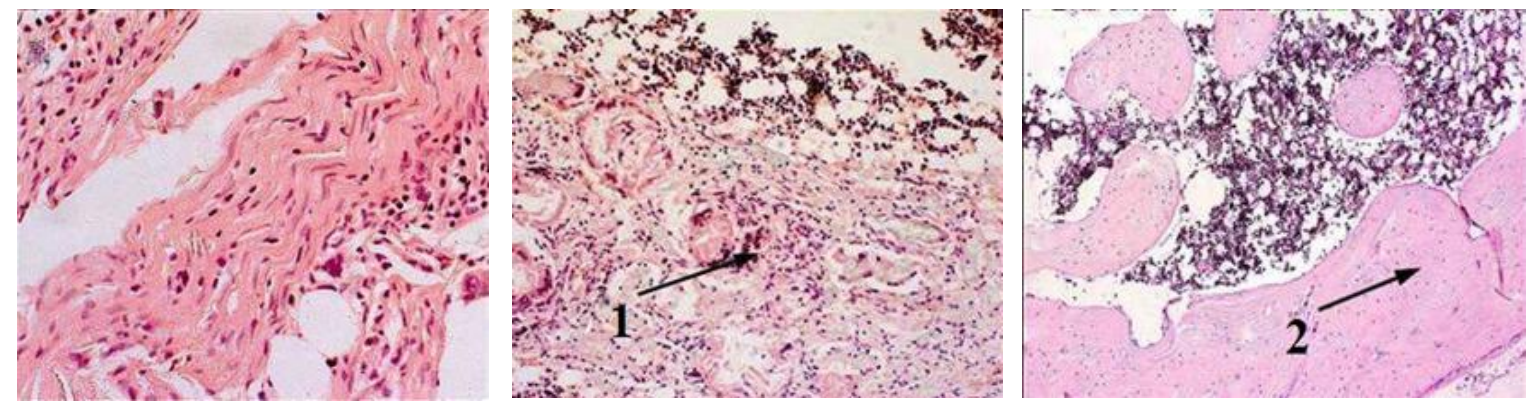

Figure 2. - Histological sections of bone tissue in the area of the simulated bone defect in the dynamics of the experiment (30th, 60th, 90th day) in group II animals. The arrows indicate: 1 -inflammatory reaction; 2 - newly formed bone tissue. Hematoxylin-eosin staining. Magnification x 100

On the 60th day of observation in rats of group II, the bone defect was filling with coarse fibrous scar tissue, the regenerate was weakly vascularized.

At the end of the experiment (90th day) in the area of implantation of PRP was dominated by bone tissue with few osteons and loose intercellular substance. The bonemarrow canal was sharply narrowing and not closing by a covering plate. 
In rats of group III, after 30 days, in the area of the defect, during implantation of our proposed composition ("mp3 OsteoBiol" + PRP) noted perifocal inflammatory reaction, with infiltration of lymphocytes (Figure 3).

Two months later, after implantation of "mp3 OsteoBiol" + PRP, a pronounced growth of fibrous, loose, not quite mature connective tissue was visualized, with the proliferation of giant multinucleated cells, macrophages, osteoblasts and the formation of osteoids. The germination of the implanted composition by small thin-walling blood vessels of the capillary type was observing. The formation of dense fibrous connective tissue, which in its structure resembled periosteum was examined on the periphery, and its cells had the appearance of osteoblasts, which is a sign of the beginning of the process of reticulofibrous bone tissue replacement by lamellar, reducing the size of the implanted composition by $60 \%$.
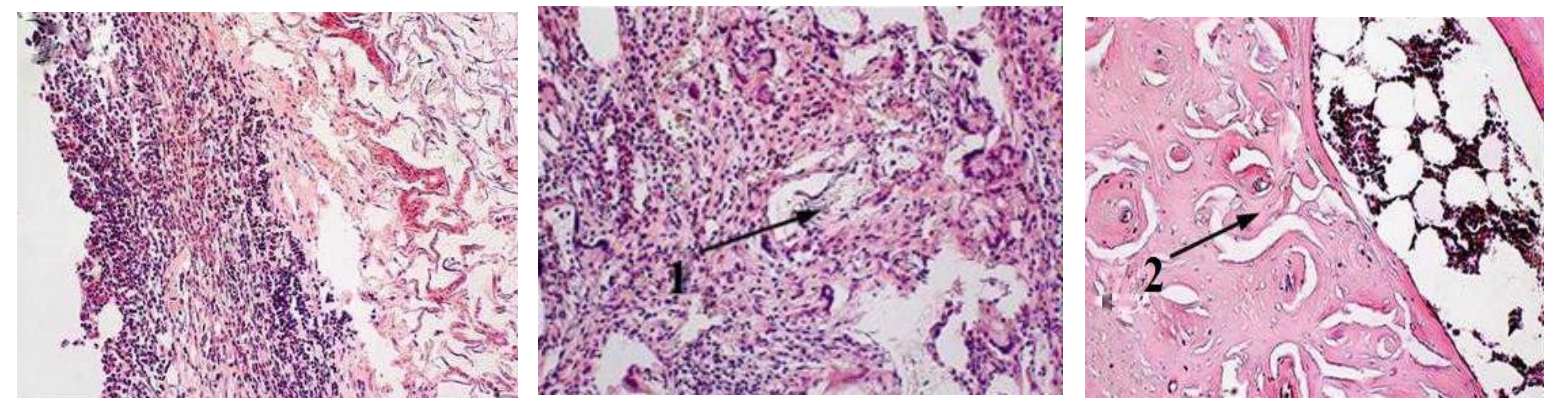

Figure 3. - Histological sections of bone tissue in the area of the simulated bone defect in the dynamics of the experiment (30th, 60th, 90th day) in group III animals. The arrows indicate: 1 -implanted composition; 2 - newly formed bone tissue.

At the end of the experiment (90th day) in the bone regenerates of animals of group III noted the active formation of the newly formed bone lamellar structure, the formation of osteons, the bone marrow canal was filled with bone marrow.

\section{DISCUSSION}

Degenerative changes in bone tissue occur as a result of violations of the normal kinetics of inflammatory-reparative reactions when bone damaging. According to some authors, the violation of the phase of proliferation and differentiation of cellular elements under the influence of various external factors, changes the intensity of the regenerative process [18]. The result is hyper - or hyporegeneration [19]. Data from modern research on the process of osteohistogenesis, methods and tools that control bone regeneration are needed to understand the essence of this problem, especially on the role of reactive changes in connective tissue in development regeneration process [20]. Based on the published data, numerous classifications of the stages of bone regeneration have been formulating.

The current state of methodological approaches to the problem of bone regeneration allows a more detailed study of the process, so the concept of stage-zonal nature of bone regeneration, has been further developed in the works of domestic and foreign scientists [21].

Currently, osteotropic drugs are widely used for zonal bone regeneration. They have high biocompatibility, activating osteoblasts, stimulate tissue differentiation and create an optimal environment for their functioning, stimulate the synthesis of new procollagen and collagen, and provide targeted delivery of essential active substances, which contributes to the repair of the destruction zone [22].

The proposed composition "mp3 OsteoBiol + PRP" had a positive effect on the histological structure of experimental rats of group III. The obtained results testify to the high 
potential of the proposed composition as a bone plastic material to improve osteogenesis and its suitability for the restoration of bone defects.

All the positive properties of drugs with osteotropic action, allow for the development of new compositions to stimulate the processes of repair and revitalization with their subsequent introduction into dental practice.

\section{CONCLUSIONS}

Thus, according to histological studies, it was found that our proposed composition, containing "mp3 OsteoBiol" and PRP, accelerated the process of bone regeneration, compared with the groups where the above agents were used alone, without inflammation, with the formation of bone, which has mature in nature.

\section{REFERENCES}

1. Barbosa-Ribeiro M., Arruda-Vasconcelos R., de-Jesus-Soares A., Zaia A. A., Ferraz C., de Almeida J., \& Gomes B. Effectiveness of calcium hydroxide-based intracanal medication on infectious/inflammatory contents in teeth with post-treatment apical periodontitis. Clinical oral investigations. 2019; 23(6):2759-2766.

2. Gaviño Orduña J. F., Caviedes-Bucheli J., Manzanares Céspedes M. C., Berástegui Jimeno E., Martín Biedma B., Segura-Egea J. J., \& López-López J. Use of Platelet-rich Plasma in Endodontic Procedures in Adults: Regeneration or Repair? A Report of 3 Cases with 5 Years of Follow-up. Journal of endodontics.2017;43(8):1294-1301.

3. Alagl A., Bedi S., Hassan K., \& AlHumaid J. Use of platelet-rich plasma for regeneration in non-vital immature permanent teeth: Clinical and cone-beam computed tomography evaluation. The Journal of international medical research.2017; 45(2):583-593.

4. Uribarri A., Bilbao E., Marichalar-Mendia X., Martínez-Conde R., Aguirre J. M., \& Verdugo F. Bone Remodeling around Implants Placed in Augmented Sinuses in Patients with and without History of Periodontitis. Clinical implant dentistry and related research.2017;19(2):268-279.

5. Lysokon Ju. Y., Iskiv M. O., Luchinsky M. A. Dynamics of X-Ray Indicators in Patients with Destructive Forms of Apical Periodontitis in Long-Term Treatment. Ukr. ž. med. bìol. Sportu. 2021;6(3):277-284.

6. Al-Hamed F. S., Abu-Nada L., Rodan R., Sarrigiannidis S., RamirezGarcialuna J. L., Moussa H., Elkashty O., Gao Q., Basiri T., Baca L., Torres, J., Rancan L., Tran S. D., Lordkipanidzé M., Kaartinen M., Badran Z., \& Tamimi F. (Differences in plateletrich plasma composition influence bone healing. Journal of clinical periodontology. 2021; 10.1111/jcpe.13546. Advance online publication.

7. Mirapoglu S. L., Guler E. M., Tok O. E., Aydogdu I., Cay A., Camli M. F., Kocyigit A., Canter H. I., \& Yildiz K. Effects of Platelet Rich Plasma and Amniotic Cell Culture Medium on Wound Healing Following Experimental Animal Tracheal Injury Model: A Comparative Study. The Journal of craniofacial surgery. 2021;32(5):1937-1941.

8. Ebadifar A., Eslamian L., Motamedian S. R., Badiee M. R., Mohaghegh S., Farahani M., Mohebbi Rad M., Mohammad-Rahimi H., \& Khojasteh A. Effect of mesenchymal stem cells with platelet-rich plasma carriers on bone formation after rapid maxillary expansion: An Animal Study. 2021. Orthodontics \& craniofacial research, 10.1111/ocr.12518. Advance online publication.

9. Goldman E., Reich E., Abramovitz I., \& Klutstein M. Inducing Apical Periodontitis in Mice. Journal of visualized experiments. 2019);JoVE:(150), 10.3791/59521.

10. Nakajima D., Tabata Y., \& Sato S. Periodontal tissue regeneration with PRP incorporated gelatin hydrogel sponges. Biomedical materials (Bristol, England). 2015; 10(5).

11. Apparaju V., Velamati S. C., Karnati L., Salahshoor A., Nateghi F., \& Vaddamanu S. K. (Does residual bone thickness apical to periodontal defect play a major role 
in maxillary sinus mucous membrane thickness?: A cone-beam computed tomographyassisted retrospective study. Dental research journal. 2019;16(4):251-256.

12. Moreno Rodríguez J. A., Ortiz Ruiz A. J., \& Caffesse R. G. Periodontal reconstructive surgery of deep intraosseous defects using an apical approach. Non-incised papillae surgical approach (NIPSA): A retrospective cohort study. Journal of periodontology. 2019;90(5):454-464.

13. Portela G. S., Cerci D. X., Pedrotti G., Araujo M. R., Deliberador T. M., Zielak J. C., Costa-Casagrande T. A., Gonzaga C. C., \& Giovanini A. F. L-PRP diminishes bone matrix formation around autogenous bone grafts associated with changes in osteocalcin and PPAR $-\gamma$ immunoexpression. International journal of oral and maxillofacial surgery. $2014 ; 43(2): 261-268$.

14. Hirota M., Matsui Y., Mizuki N., Kishi T., Watanuki K., Ozawa T., Fukui T., Shoji S., Adachi M., Monden Y., Iwai T., \& Tohnai I. Combination with allogenic bone reduces early absorption of beta-tricalcium phosphate (beta-TCP) and enhances the role as a bone regeneration scaffold. Experimental animal study in rat mandibular bone defects. Dental materials journal. 2009;28(2):153-161.

15. Mariano R., Messora M., de Morais A., Nagata M., Furlaneto F., Avelino C., Paula F., Ferreira S., Pinheiro M., \& de Sene J. P. Bone healing in critical-size defects treated with platelet-rich plasma: a histologic and histometric study in the calvaria of diabetic rat. Oral surgery, oral medicine, oral pathology, oral radiology, and endodontics. 2010;109(1):72-78.

16. Plachokova A. S., van den Dolder J., Stoelinga P. J., \& Jansen J. A. Early effect of platelet-rich plasma on bone healing in combination with an osteoconductive material in rat cranial defects. Clinical oral implants research. 2007;18(2):244-251.

17. Turhan E., Akça M. K., Bayar A., Songür M., Keser S., \& Doral M. N. A comparison of the effects of platelet-rich plasma and demineralized bone matrix on critical bone defects: An experimental study on rats. Ulusal travma ve acil cerrahi dergisi $=$ Turkish journal of trauma \& emergency surgery: TJTES. 2017;23(2):91-99.

18. Zhang Y., Yu J., Zhang J., \& Hua Y. Simvastatin With PRP Promotes Chondrogenesis of Bone Marrow Stem Cells In Vitro and Wounded Rat Achilles TendonBone Interface Healing In Vivo. The American journal of sports medicine. 2019;47(3):729739.

19. Yin W., Qi X., Zhang Y., Sheng J., Xu Z., Tao S., Xie X., Li X., \& Zhang C. Advantages of pure platelet-rich plasma compared with leukocyte- and platelet-rich plasma in promoting repair of bone defects. Journal of translational medicine. 2016; 14:73.

20. Gianakos A., Zambrana L., Savage-Elliott I., Lane J. M., \& Kennedy J. G. Platelet-Rich Plasma in the Animal Long-Bone Model: An Analysis of Basic Science Evidence. Orthopedics. 2015;38(12):e1079-e1090.

21. Delgado D., Garate A., Sánchez P., Bilbao A. M., García Del Caño G., Salles J., \& Sánchez M. Biological and structural effects after intraosseous infiltrations of agedependent platelet-rich plasma: An in vivo study. Journal of orthopaedic research: official publication of the Orthopaedic Research Society. 2020;38(9):1931-1941.

22. Lalegül-Ülker Ö., Şeker Ş., Elçin A. E., \& Elçin Y. M. Encapsulation of bone marrow-MSCs in PRP-derived fibrin microbeads and preliminary evaluation in a volumetric muscle loss injury rat model: modular muscle tissue engineering. Artificial cells, nanomedicine, and biotechnology. 2019; 47(1): 10-21. 
The work is a fragment of scientific research work of the Department of Therapeutic Dentistry Danylo Halytsky Lviv National Medical University "Development and application of new diagnostic methods, prevention and treatment of endodontic and periodontal diseases" (state registration number 0115 U000036).

Yulia Lysokon orcid.org/ 0000-0002-1722-1825

Mykhailo Luchynskyi orcid.org/0000-0001-7652-0684

Mariana Iskiv orcid.org/0000-0001-5589-1160

\section{CORRESPONDING AUTHOR}

\section{Yulia Lysokon}

Department of Therapeutic Dentistry, Danylo Halytsky Lviv National Medical University, Lviv, Ukraine

Address: Pekarska 69, Lviv 79010, Ukraine

phone +0979249593 